\title{
1995128358
}

\section{Towards a Framework of Human Factors Certification of Complex Human-Machine Systems}

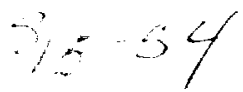

\author{
Birgit Bukasa
}

Austrian Road Safety Board

\section{Background}

The recognition of the importance of human factors to system safety, especially in aviation, is constantly increasing. Foushee (1993), in his keynote address at the International Civil Aviation Organization (ICAO) Flight Safety and Human Factors Symposium, even talked about the "human factors revolution", emphasizing how quickly human factors thinking has infiltrated the world of aviation and high technology in some parts of the world. Consequently, human factors concepts have to become institutionalized into the aviation culture. In order for this to occur, the FAA (in its 1990 National Plan for Aviation Human Factors) amongst others is placing stronger emphasis on human factors as part of aircraft and avionics certification requirements (Foushee, 1993).

This claim for stronger consideration of human factors principles in the designs of complex and integrated man-machine systems, or at least of the human computer interfaces, is the reaction to changes and foreseen further future changes in the aeronautical world. These changes have and will have a great impact not only on the aviation community, especially the operators such as pilots or air traffic controllers, but also on the society as a whole.

Advanced automation in aviation, including its implications for the users as well as for safety concerns, is the main point at issue. It has evoked considerable controversy among the different groups involved, the users, the manufacturers, the scientists and the regulatory agencies. Scardigli (1991) identified antagonistic mental representations of designers, pilots and air traffic controllers concerning their present and future role, their vision of the ideal flight and desirable future changes as major roots for this controversy illustrating the struggle for power in the aeronautical world at the same time.

Besides, aircraft accident/incident analysis in aviation, as well as in other non-aviation environments (e.g. nuclear power accidents, ferry, tanker or train accidents), identify human performance problems, the so-called "human error", as major contributing factor. Taking the expected future air traffic growth into consideration, this would lead, in the next couple of decades, to a major aviation accident every week despite considerable improvements in technology (Foushee, 1993).

Undoubtedly, this very broad categorization called "human error" caused a lot of misunderstandings. Berninger (1991), for example, tried to clarify the role of human error in aircraft accidents by stating that the conclusion of human error only proves that the human 
could have prevented the accident but not that the human (pilot) caused it. Instead, he argues that the system characteristics working against human performance cause the human to fail.

According to Foushee (1993), there is enough evidence that the automation philosophy automation being an easy way to remove human error from the system - has to be critically examined and that new, more "human-centered" approaches to automation have to be considered. Berninger (1991) emphasized that systems which are compatible with humans seem to be a promising approach to further system safety improvements.

The idea of human factors certification has to be seen in this context. One approach to reaching the goal of generally more human-centered automation or technology is by putting pressure on system designers to incorporate human factors considerations into the design process.

\section{Definition of Terms}

According to the Austrian law of accreditation (Austrian Standards Institute, 1992), certification is defined as the formal certificate of conformity carried out by accredited independent representative impartial third persons or bodies. Certification is a forced legal act based on documented and accepted rules, procedures and processes. It is the end and result of a process of checking whether the subject of certification fulfills defined requirements.

Certification is, above all, a measure of quality assurance, often connected with safety goals. Only those products or systems which have proven their conformity to safety goals are allowed into operation. Thereby, the period of validity of certification might be limited or unlimited according to the subject of the certification.

Human factors certification is just a specification of the subject that has to be certified. It is meant in the sense of certification of human factors. Following this understanding, human factors certification means to certify human factors issues as part of general system certification. Therefore, the above mentioned general definition and principles of certification are valid too.

\section{Problems of Human Factors Certification}

At the Congress of the German Psychological Society held in Zurich in 1980 Bischof called for the "Galileo of psychology" meaning that psychology is still in the stage of astronomy at the end of the 15th century (cited after Barglik, 1993). While the natural sciences or technical disciplines progress in a more and more accelerating way, plunging into areas like artificial intelligence, virtual reality or non-linear self organizing systems, the behavioral sciences in general have no substantial impact on research programs determining man's presence or future.

This leads to the question of whether psychology or behavioral sciences in general already have a sufficient level of sophistication in order to carry out human factors certification. Are there ways to asses human factors other than by certification? It might be more fruitful to 
improve established procedures instead of introducing human factors certification. Especially in the aviation environment, there are established procedures concerning aircraft, accidents, operation and people which might be corrected or extended (e.g., Paries, 1994).

\section{What makes human factors certification so difficult?}

One of the particular problems of behavioral sciences are the so-called "soft data." Human behavior is not deterministic but rather probabilistic by nature. Human behavior depends on a lot of conditions from inside the individual and the outside world, from past experience and future plans and expectations, from man's interactions with others but also from social, political and economical conditions and developments. Humans are in a permanent process of adapting themselves to the external world as well as adapting the external world to their needs. Therefore, measuring methods, results and predictions are not that exact in behavioral sciences compared to natural sciences.

This leads to basic questions about human factors certification: which degree of certainty is certain enough, how to define human factors standards, how to consider cultural differences, where to set cut-offs, is it enough to identify components which are negative or is it necessary to distinguish between optimal and still acceptable solutions and what is the price for it, e.g., the loss of safety?

Undoubtedly, focusing on human factors certification is something new. Until now, the activities of the national and international standardization bodies are concentrated on testing, inspection and certification of products, processes, services and quality systems from a machine-centered engineering point of view. Human factors aspects primarily flew into ergonomical standards, e.g., standards for the optimal physical layout and anthropometry of operators' workstations. Concerning standards for quality management and quality system elements (e.g., ISO 9004-2), human factors are restricted to education and training requirements as well as to measures enhancing the motivation of service personnel.

\section{Approach to Human Factors Certification}

Starting with human factors certification, there is a great deal of work to do. The what, how, when, where and who questions have to be thoroughly discussed during the workshop, but the workshop was just the beginning. Therefore, this paper cannot present solutions to all the open questions. It can only point to some aspects which seem to be important.

\section{Guidelines of Human Factors Certification}

As a first step, guidelines of human factors certification have to be established by a multidisciplinary working group (including human factors experts, designer, user, representative of regulatory authority, expert from Standards Institute). These guidelines have to refer to the prerequisites of certification which are the goals, criteria, measures, methods, processes, standards, testers, test procedures, check and examination system and penalties. It is necessary to keep the specification of these prerequisites general and descriptive, not only in 
order to be valid for different man-machine applications, but also because of lack of experience with human factors certification considering the problem of soft data as well.

At the beginning, human factors certification should aim at minimum standards and at eliminating poor design. It should not aim at average or maximum standards which are far more difficult to check. This is according to the certification practice in general.

\section{Model of Human-Centered System Issues}

In the context of what should be certified, a general model of human-centered system issues which can be applied to different man-machine systems is an important aid. Harwood (1993), for example, introduced an approach distinguishing three broad categories of human-centered system issues which all have to be considered. These categories, which have to be specified according to the context of domain (e.g., ATC, flightdeck, power plant), are technical usability, domain suitability, and user acceptance.

Technical usability refers to perceptual and physical aspects of the human computer interface. Domain suitability refers to the content of information and display representation for domain tasks as well as functionality and decision-aiding algorithms. Finally, user acceptability refers to the ease of use and suitability of the system for supporting cognitive task requirements as well as to aspects of job satisfaction (Harwood, 1993).

Based on such a model, a comprehensive list of relevant human factors requirements can be elaborated for each new system.

\section{Tools for Human Factors Certification}

Common tools for certification purposes are handbooks which are available for human factors. Yet, they are not sufficient.

Even if they cover a very broad area of knowledge, human factors is evolving so rapidly that any test more than a decade old cannot do justice to its current state (Kantowitz, 1993). Moreover, considering the specificity of human behavior and the strong influence of the physical and social environment on man's behavior which was demonstrated by the work of Mischel (e.g., 1971, 1973), handbooks are of limited value in order to evaluate new system from a human-centered point of view. General human factors principles have to be adapted, modified and evaluated in regard to the specific application.

Due to the limited value of handbooks, it is necessary to strongly focus on empirical data, revealed by testing and evaluation, especially on validation studies.

Validation was thoroughly discussed at the NATO ASI in Portugal, 1992 (Wise, Hopkin, \& Stager, 1993). Based on this, a lot of information is available on how to check and evaluate validation results.

\section{Institutionalization of Human Factors Certification}

There are several possibilities regarding how to institutionalize human factors certification. At least from an Austrian perspective, the most realistic way is to establish a collaboration with the existing national standardization bodies which are members of the ISO (International 
Standardization Organization) in order to link human factors certification as close as possible to existing certification.

Persons or institutes who or which are qualified should be accredited. One might refer to guides like the EN 45011-13 or the ISO/IEC Guide 40 on general requirements for the acceptance of certification bodies.

\section{Conclusions}

As far as total automation is not realized, the combination of technical and social components in man-machine systems demands not only contributions from engineers but at least to an equal extent from behavioral scientists. This has been neglected far too long. The psychological, social and cultural aspects of technological innovations were almost totally overlooked.

Yet, along with expected safety improvements the institutionalization of human factors is on the way. The introduction of human factors certification of complex man-machine systems will be a milestone in this process.

\section{References}

Austrian Standards Institute (1992). Law of Accreditation. Vienna: Austrian Standards Institute.

Barglik, W. (1993). Can the theory of nonlinear systems give input to models of development of tests? In B. Bukasa \& U. Wenninger (Eds.), 3.ART-90 Workshop. Vienna: Austrian Road Safety Board.

Berninger, D. J. (1991). Understanding the role of human error in aircraft accidents. (Transportation Research Record 1298, 33-42).

EN45011-13 (1989). General criteria for certification bodies operating product certification. Brussels: European Community.

Foushee, C. (1993). The human factors revolution: Meaningful change or temporary infatuation? In ICAO (Ed.) Human Factors Digest No.9. Proceedings of the Second ICAO Flight Safety and Human Factors Global Symposium (ICAO Circular 243-AN/146, 11 30).

Harwood, K. (1993). Defining human-centered system issues for verifying and validating air traffic control systems. In J.A. Wise, V. D. Hopkin, \& P. Stager (Eds.), Verification and Validation of Complex Systems: Human Factors Issues, NATO ASI Series. Berlin: Springer-Verlag.

ISO/IEC Guide 40 (1983). General requirements of the acceptance of certification bodies. Geneva: International Standards Organization.

ISO 9004-2 (1991). Quality management and quality system elements--guidelines for services. Brussels: European Community. 
Kantowitz, B. H. (1993). Human factors knowledge requirements for flight crews. In ICAO (Ed.), Human Factors Digest No.9, Proceedings of the Second ICAO Flight Safety and Human Factors Global Symposium (ICAO Circular 243-AN/146, A-29-34).

Mischel, W. (1973). Toward a cognitive social learning reconceptualization of personality. Psychological Review, 80(4), 252-283.

Mischel, W. (1971). Introduction to personality. New York: Holt, Rinehart \& Winston.

Paries, J. (1993, July). Some inadequacies of current human factors certification process of advanced aircraft technologies. Paper presented at the International Workshop on Human Factors Certification of Advanced Aviation Systems, Bonas.

Scardigli, V. (1991, October). Automation in aeronautics: A French research program. In M. C. Dentan \& P. Lardennois (Eds.), Human Factors for Pilots. Report on the XIX Conference on the Western European Association for Aviation-Psychology.

Wise, J. A., V. D. Hopkin, \& P. Stager (Eds.), Verification and Validation of Complex Systems: Human Factors Issues. NATO ASI Series. Berlin: Springer-Verlag. 